\title{
Cross-Talk Between the Immune System and Tuberculosis Pathogenesis; A Review With Emphasis on the Immune Based Treatment
}

\author{
Mohammad Reza Javan ${ }^{1}$, Ahmad Ali Jalali Nezhad ${ }^{2}$, Sarieh Shahraki ${ }^{2}$, Amin Safa ${ }^{1}$, Halimeh Aali ${ }^{3 *}$, \\ Zohre Kiani $^{4}$ \\ 'Department of Immunology, Faculty of Medicine, Zabol University of Medical Sciences, Zabol, Iran \\ ${ }^{2}$ Department of Physiology, Faculty of Medicine, Zabol University of Medical Sciences, Zabol, Iran \\ ${ }^{3}$ Department of Internal Medicine, Faculty of Medicine, Zabol University of Medical Sciences, Zabol, Iran \\ ${ }^{4}$ Student Research Committee, Kerman University of Medical Sciences, Kerman, Iran
}

\section{*Correspondence to}

Halimeh Aali, Department of Internal

Medicine, Faculty of Medicine, Zabol

University of Medical Sciences,

Zabol, Iran.

Email: ali@zbmu.ac.ir

Received July 10, 2016

Revised September 7, 2016

Accepted November 9, 2016

Published online November 21, 2016

Please cite this article as follows: Javan MR, Jalali Nezhad AA, Shahraki S, Safa A, Aali H, Kiani Z. CrossTalk between the immune system and tuberculosis pathogenesis; a review with emphasis on the immune based treatment. Int J Basic Sci Med. 2016;1(2):4047. doi:10.15171/ ijbms.2016.10.

\section{Abstract}

As a globally major health problem, tuberculosis (TB) causes almost two million cases of death annually. Epidemiological studies demonstrate that a third of the world's individuals is infected with Mycobacterium tuberculosis. Approximately $10 \%$ of infected patients with M. tuberculosis develop chronic manifestation as TB. Due to HIV coinfection and emerging the drug-resistant TB, the disease has been increasing and its control has been frustrated in several parts of the world. Current diagnostic techniques and therapeutic tools for TB are not satisfactory. Consequently, it is urgently essential to establish new therapies concerning vaccines, immunotherapeutic agents to provide prosperous attempts for TB controlling. To achieve this goal, it is required to be armed with comprehensive understanding of immunobiology and immunopathogenesis of TB. This would be beneficial in designing new immune-based protections, drug discoveries, personalized medicine by choosing highly-effective immunotherapeutic interventions, identification and development of novel drug candidates. Hopefully, immunotherapies could be advantageous in modulating the immune system in patients with TB, providing efficient control of M. tuberculosis infection perpetuation and, therefore, its pathogenesis. This review herein attempts to describe the function of immune system in response to TB that is of the therapeutical and clinical importance. Moreover, new insights based on therapeutics to resolve TB with immunological orientation will be discussed.

Keywords: Mycobacterium tuberculosis, Tuberculosis, Therapeutic agents, Immune system.

\section{Introduction}

Tuberculosis (TB) is a major global health issue and one of the leading causes of death mediated by infectious agents. Despite enormous efforts to control the disease, estimations show that there are about 9 million new cases of $\mathrm{TB}$ infection with 1.5 million deaths per year. ${ }^{1}$ Although TB affects several organs of the body, it majorly and specifically affects the lungs. In most circumstances, infections with Mycobacterium tuberculosis do not demonstrate symptoms and clinical manifestations, which is known as latent tuberculosis (LTBI). However, almost $10 \%$ of cases with latent infections further develop to active disease. The most common clinical symptoms of active TB include a prolonged cough combined with blood-containing sputum, sweating, fever, and weight loss. ${ }^{2}$

Initiation of $\mathrm{TB}$ infection occurs once M. tuberculosis reaches the pulmonary alveoli, where the bacterium invades and then replicates within the endosomes of alveolar-resident macrophages. The behavior of immune response determines the fate of infection by modifying the rate of actively replicating $M$. tuberculosis in patients with concomitant alterations in TB disease risks. During latent and early activated phases of $\mathrm{TB}$, the infection is mainly intracellular and, consequently, T-cell responses play important roles for

Copyright (C) 2016 The Author(s); Published by Zabol University of Medical Sciences. This is an open-access article distributed under the terms of the Creative Commons Attribution License (http://creativecommons.org/licenses/by/4.0), which permits unrestricted use, distribution, and reproduction in any medium, provided the original work is properly cited. 
the protective immunity. In this immune response, $\mathrm{CD}^{+}$ $\mathrm{T}$ cells as well as $\mathrm{CD}^{+}$helper $1 \mathrm{~T}$ cells (Th1) through producing cytokines including tumor necrosis factor (TNF)- $\alpha$, interferon (IFN)- $\gamma$, and interleukin (IL)-2 participate in controlling the M. tuberculosis replication. ${ }^{3-5}$ Development of TB is likely due to dysregulated immune response as well as impaired immune regulation. In addition, a bulk of the lung damage related to TB is due to host-mediated immunopathology instead of direct virulence factors derived from $M$. tuberculosis. The modulation of immune regulation through divergence of a protective response by Th1 and $\mathrm{CD} 8^{+} \mathrm{T}$ cells, with Th2-related cytokines, TGF- $\beta$, regulatory T cells (Treg), and other immunosuppressive mediators is a key player in this regard..$^{6-8}$ Thus, host-directed therapy by applying immunomodulators might be a promising therapeutic approach to control TB. This paper aimed to focus on the immunology of TB and the immune-based therapies to control this disease.

\section{Methods}

Mechanisms of the Innate Immunity to M. tuberculosis Following M. tuberculosis entrance into the host lungs, the surface antigens interact with several receptors like pattern recognition receptors (PRRs) including toll-like receptors (TLRs), ${ }^{9}$ mannose receptor, ${ }^{10}$ complement receptor 3 (CR3), ${ }^{11}$ scavenger receptor, ${ }^{10}$ and dendritic cell (DC)-specific intercellular-adhesion-molecule-3grabbing non-integrin (DC-SIGN), which are commonly located on the surface of macrophages and DCs. The antigens of $M$. tuberculosis which are recognized with these receptors include $\mathrm{CpG}$-containing DNA, lipoprotein, phosphatidylinositol mannoside, and mannose-capped lipoarabinomannan. Furthermore, M. tuberculosis surface lipoarabinomannan is recognized by the pulmonary surfactant protein D (SP-D), resulting in limitation of the intracellular growth of $M$. tuberculosis by means of promoted infusion of phagosome and lysosome. ${ }^{12}$ Moreover, there is a cooperation among TLR-2, C-type lectin dectin-1 that interacts with $M$. tuberculosis, and cytosolic nucleotide binding and oligomerization domain-like receptors like NOD2 that binds to muramyl dipeptide, which eventuates in activation of the nuclear factor-kappa B (NF- $\mathrm{kB}$ ) signaling pathway, which in turn facilitates the production of pro-inflammatory cytokine. ${ }^{13}$ The cytokines which are produced and secreted upon the activation of NF- $\kappa B$ include IL-1, IL-12, IL-18, TNF- $\alpha$, and chemokines. These chemokines mediate the recruitment of immune cells such as natural killer (NK) cells, neutrophils, T cells, DC, and macrophages to the infected tissue. ${ }^{14,15}$ M. tuberculosis secrets protein ESAT6, which suppresses the activation of NF-kB signaling pathway by inhibiting the interaction of MyD88 with the downstream molecule, namely, interleukin-1 receptorassociated kinase 4(IRAK4) ${ }^{16}$ Activation of TLR signaling causes up-modulation of expression of both the vitamin D receptor $(\mathrm{VDR})$ and the vitamin $\mathrm{D}$-1-hydroxylase genes, which mediate the conversion of pro-vitamin $\mathrm{D}$ into the active form of vitamin $\mathrm{D}, 1,25(\mathrm{OH}) 2 \mathrm{D} 3$. Overexpression of these genes ultimately eventuates in production of the antimicrobial peptides such as $\beta$-defensin and cathelicidin to kill the intracellular pathogen. ${ }^{17-20}$ On the other side, activation of DC-SIGN signaling causes the production of immunosuppressive cytokines like IL-10 and transforming growth factor (TGF)- $\beta .^{14}$

Macrophages are heterogeneous and play different roles during immune response toward $M$. tuberculosis infection. The type 1 IL-23-producing macrophages promote a protective Th1 mediated immunity against infection, and type 2 IL-10-producing macrophages play a role in the suppression of immune response to M. tuberculosis. ${ }^{21}$ In addition, type 2 macrophages participate in the induction of $\mathrm{CD} 4^{+} \mathrm{T}$ cells to be converted to $\mathrm{CD} 25^{+} \mathrm{FoxP} 3^{+} \mathrm{mTGF} \beta$ $1^{+}$Tregs, which further suppress the immune system. ${ }^{22}$

Activated T cells and NK cells both secret IFN- $\gamma$ which plays a role in the activation of macrophages to kill bacteria by promoting the phagosomal maturation and production of reactive oxygen species (ROS) and reactive nitrogen intermediates. ${ }^{23,24}$ While IFN $-\gamma$ contributes to the fusion of phagosome and lysosome by cell signaling pathway IRGm1 (LRG-47) 25,26 and PI3K, ${ }^{27}$ both IL-4 and IL-13 secreted by Th2 inhibit autophagy-associated killing of bacteria by Akt signaling pathway. ${ }^{28}$ TNF-ahas also a role in killing the intracellular M. tuberculosis by activating the reactive nitrogen species (RNS), thereby participating in the development of granuloma. ${ }^{29}$

Neutrophils are the first immune cells attracted to the infected sites that express many surface receptors as well as antimicrobial agents. ${ }^{14}$ In vitro experiments on neutrophils demonstrate that these cells are activated during incubation with $M$. tuberculosis and are capable of limiting the bacterial growth. ${ }^{29}$. Neutrophils produce the cathelicidin LL-37, human neutrophil peptides 1-3, and lipocalin 2, which can either kill or limit the growth of $M$. tuberculosis. ${ }^{30}$ On the other hand, apoptotic neutrophils have a role in the activation of macrophages by producing the heat shock protein $72,{ }^{31}$ and granule proteins. ${ }^{32}$ Interestingly, some studies have suggested that neutrophils have no beneficial roles in infection with $M$. tuberculosis and show a pathological function rather than a protective role in the control of active $\mathrm{TB}^{30,33}$ (Figure 1).

Mechanisms of the Adaptive Immunity to M. tuberculosis DCs and macrophages infected with M. tuberculosis are common antigen presenting cells (APCs), which present bacterial antigens to $\mathrm{T}$ and $\mathrm{B}$ cells of the adaptive immunity. It has been shown that IL-12p40 plays an important role in the activation of pulmonary DC during pathogen induced stimulation. ${ }^{34}$ Furthermore, more efficient antigen presentation could occur by released apoptotic vesicles from the macrophage apoptosis procedures that provide bacterial antigens to primary mycobacteria uninfected DCs. Activation of $\mathrm{CD}^{+} \mathrm{T}$ cells can be diminished by decreased antigen delivery through blocking the macrophage apoptosis. ${ }^{35}$

The protective immune response by adaptive immunity 

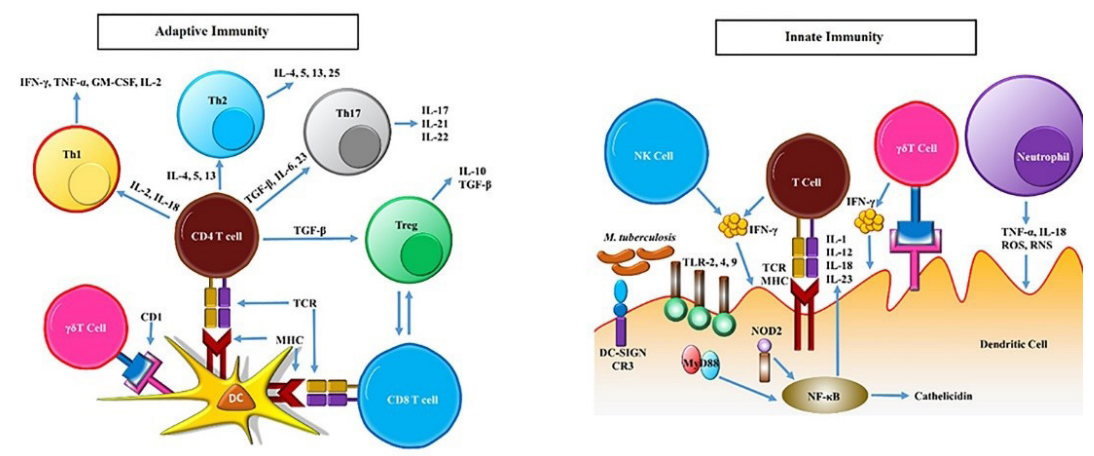

Figure 1. Cells and Molecules Involved in the Adaptive and Innate Immunity Against Mycobacterium tuberculosis.

during $M$. tuberculosis infection is carried out by the MHC restricted $\mathrm{CD}^{+}$and $\mathrm{CD}^{+}{ }^{+} \mathrm{T}$ cells as well as $\gamma-\delta$ $\mathrm{T}$ lymphocytes, which participate in IFN- $\gamma$ production. Thus, $\mathrm{CD} 4^{+} \mathrm{Th} 1$ cells are major players in TB protection and demonstrate powerful IFN- $\gamma$ response, compared with $\mathrm{CD}^{+} \mathrm{T}$ cells in patients with mycobacterial infection. ${ }^{36,37}$ Moreover, depletion of $\mathrm{CD}^{+} \mathrm{T}$ cells in $M$. tuberculosis infection culminates in the procrastinated chemotaxis of activated $\mathrm{CD}^{+} \mathrm{T}$ cells from the lymph nodes, resulting in the impaired immune protection. ${ }^{38}$ During $M$. tuberculosis infection, $\mathrm{CD}^{+} \mathrm{T}$ cells can differentiate into several subtypes of Th1, Th2, Th17, and even regulatory $\mathrm{T}$ (Treg) cells. Cytokines produced by Th1 cells, namelyIL- 2 , IFN- $\gamma$, TNF- $\alpha$, TNF- $\beta$, and granulocyte-monocyte colony-stimulating factor (GMCSF)cause further differentiation and activation of Th1 cells, cytotoxic $\mathrm{T}$ lymphocytes (CTL), macrophages, and granulocytes. On the other hand, Th2 cytokines including IL-4, IL-5, IL-6, IL-9, andIL-13 cause activation and stimulation of $\mathrm{B}$ cells, providing antibody response. Additionally, Th2 cytokines suppress the Th1 associated immune response, that mediates a non-protective immune response toward TB. The Th17 cells play a role in the early phase of inflammatory response by producing specific cytokines such as IL-17F, IL-21, and IL-22. These cytokines are involved in the production of defensin as well as recruitment of inflammatory cells like neutrophils and monocytes to the site of infection. ${ }^{39-41}$

Tregs mainly belong to $\mathrm{CD} 4^{+} \mathrm{CD} 25^{+} \mathrm{FoxP} 3^{+} \mathrm{T}$ cells, which suppress numerous mechanisms of immune response by producing IL-10 and TGF- $\beta .^{42,43}$ Moreover, CD8 ${ }^{+}$Treg cells are involved in the inhibition of $\mathrm{T}$ cell proliferation and function. ${ }^{44}$ Tregs play a role in the modulation of $\mathrm{CD}^{+} \mathrm{T}$ cell differentiation to the Th1, Th2, or Th17 subsets. The natural FoxP3 expressing Tregs have been observed to show greater expansion during M. tuberculosis infection. ${ }^{45}$ These cells participate in the inhibition of IFN- $\gamma$ production from $\gamma / \delta$ memory T cells responding to antigens from $M$. tuberculosis. ${ }^{46}$ Treg cells also mediate their action by producing TGF- $\beta$, which prevents the activation and proliferation of $\mathrm{CD} 4{ }^{+} \mathrm{T}$ cell, ${ }^{47}$ facilitating mycobacterial infection dissemination and therefore, exacerbation of infection manifestations. ${ }^{48,49}$ Increased numbers of Treg cells have been observed in patients with active TB, ${ }^{49}$ and depletion of Treg cells has been observed to improve the protective efficacy of vaccines toward infection with M. tuberculosis..$^{50,51}$

For many years, B cells have been thought to have little impact in protection against TB. Animal studies have revealed a beneficial role of $\mathrm{B}$ cells through interactions with players of the cellular immunity as well as activation of complements, which provide an optimal protection in mice with $M$. tuberculosis infection. ${ }^{52,53}$ Activation of the three complement alternative, classical, and lectin pathways by Bacillus Calmette-Guérin (BCG) causes the fixation of the main complement component of $\mathrm{C} 3 \mathrm{~b}$ on the surface antigens of bacteria, contributing to phagocytosis and killing of mycobacteria. ${ }^{54}$

Various profiles of secreted cytokines during $M$. tuberculosis infection determine the fate of $\mathrm{CD}^{+} \mathrm{T}$ cell differentiation and therefore play roles in the beneficial or deleterious quality of immune response to TB. A protective Th1 related response is mediated by IFN- $\gamma$, IL-12, and IL-18, whereas Th2 development is carried out by another cytokine set including IL-4, IL-5, and IL-13. TGF- $\beta$ in lower doses alongside with IL-6, IL-21, and IL-23 are involved in Th17 development; however, TGF- $\beta$ at higher concentrations in combination with IL-2 promote Treg differentiation. ${ }^{42,43}$ IL- 6 is involved in inflammatory responses by suppressing the TGF- $\beta$ induced Treg cell development as well as by inducing the Th17 differentiation alongside with TGF- $\beta^{55}$ (Figure 1).

\section{Results}

Immune System-Based Therapeutics of Tuberculosis Other Uncommon Mycobacteria

Application of Mycobacterium vaccae as an immunotherapeutic tool has been shown. Investigations demonstrated that single injection of $M$. vaccae could increase the conversion of sputum culture after 1 month and cause a significant improvement, regarding the radiographic manifestations, after 6 months. ${ }^{56}$ However, a study could not show the beneficial effects of $M$. vaccae injection..$^{57}$ On the other hand, a meta-analysis concluded that intradermal injection of $M$. vaccae based immunotherapy was beneficial, considering the sputum conversion enhancement as well as amelioration of radiographic outcomes. ${ }^{58}$ In addition, enhanced sputum 
conversion in newly treated cases with TB was shown after oral administration of $M$. vaccae. ${ }^{59}$ Promising observations have been reported using other mycobacteria like M. indicuspranii in the animal models of TB. ${ }^{60}$

\section{Vaccines}

DNA vaccines have been explored to treat the TB. Several DNA vaccines, based on genes expressing $M$. tuberculosis proteins such as ESAT-6, Hsp65, and Ag85A have been indicated to have fruitful results in mice with $M$. tuberculosis infection. ${ }^{61-64}$ A developed DNA vaccine with cDNA3.1 plasmid as a vector that expresses $I L-2$ as well as Hsp65 genes that integrate into the virus-free envelopes, originated from the hemagglutinating virus of Japan. The intramuscular administration of the above-mentioned DNA vaccine that contained both $H s p 65$ and $I L-12$ genes resulted in the promoted survival rate of mice, which were infected with multidrug resistance (MDR) or extensively drug-resistant (XDR) TB. Moreover, almost the same beneficial effects were reported in another survey, which demonstrated that the DNA vaccine containing Hsp65 and $I L-12$ genes improved the survival rate of primates with M. tuberculosis infection. ${ }^{65}$

On the other side, vaccines containing other molecules have been explored to see if there are potential benefits. RUTI is a vaccine, which is built using the detoxified cellular fragments of M. tuberculosis and liposomes as a delivery approach. ${ }^{66}$ It has been reported that RUTI has the potential to be used as a tool for the immunotherapy and prophylaxis against $M$. tuberculosis infection in animal models. ${ }^{67}$ The immunogenicity and safety of this vaccine have been established in Phase I and II clinical trials. ${ }^{68,69}$

\section{Mesenchymal Stem Cells}

Mesenchymal stem cells (MSCs) are multipotent stromal cells that differentiate into several cell types. ${ }^{70,71}$ There are MSCs in several tissues and organs of the body like lungs, ${ }^{72,73}$ providing a potential in the repair of damaged tissues. ${ }^{74,75}$ MSCs modify a tissue with chronic inflammation to a condition with capability to stimulate a strong pathogen-specific immune response. The cell-to-cell contact as well as release of mediators like prostaglandin E2 and TGF- $\beta$ have been considered as the functional pathways of MSCs. ${ }^{76}$ Administration of MSCs during 4 weeks of TB treatment as a phase I clinical trial demonstrated beneficial effects by measuring the radiological changes. ${ }^{71}$

\section{V5 Immunitor}

V5 immunitor is derived from the blood of patients with hepatitis Band $\mathrm{C}$ virus-positive and is inactivated by chemical agents and heat. It was first developed to treat patients with chronic hepatitis B and C infections. ${ }^{77}$ It has been proposed that blood donors may have circulating M. tuberculosis cell fragments and antigens, which drive immune responsestoTB. ${ }^{78}$ Moreover, the circulating cytokines and other immune mediators from the blood of donors could increase the T-cell responses to $M$. tuberculosis. However, there may be some other unknown agents, providing adjuvant function. V5 immunitor oral therapy, during a Phase I clinical trial, culminated in a remarkable conversion of sputum culture after 1 month of treatment. ${ }^{79,80}$

\section{Cytokines and Inhibitors}

Application of IFN- $\gamma$ and IL-12 as adjuncts resulted in beneficial outcomes in some cases with MDR TB. ${ }^{81-}$ 83 Moreover, IFN- $\gamma$ administration in combination with intranasal IgA in murine models of TB caused a decreased load of $M$. tuberculosis in the lungs. ${ }^{84}$ There are controversial observations in the advantageous effects of IL-2to treat TB patients. ${ }^{85,86}$ However, intradermal injection of IL-2 to patients with MDR TB resulted in improved sputum conversion. ${ }^{87}$ Moreover, IL-2 caused an increased activity of a pyrophosphate to promote $\gamma \delta$ T cell responses as well as a diminished load of $M$. tuberculosis in the lungs of monkeys infected with the bacterium. ${ }^{88}$ AntiTNF- $\alpha$ antibodies play a role in increasing the risk of TB reactivation. ${ }^{89}$ However, anti-TNF- $\alpha$ therapy is beneficial in the patients with active TB alongside with TB multidrug therapy. The benefits of anti-TNF- $\alpha$ therapy may be mediated by increased susceptibility of $M$. tuberculosis to the bactericidal activity of other drugs. ${ }^{90}$ IL- 4 and TGF- $\beta$ blockade can improve Th1 type immunity and contribute to decline in the bacterial load of $M$. tuberculosis in the lungs of mice infected with the bacterium..$^{91,92}$

\section{Antibodies}

B-cell-deficiency causes a higher bacterial load and, therefore, severe manifestations upon $M$. tuberculosis infection. ${ }^{93,94}$ Use of monoclonal antibodies against $M$. tuberculosis antigens has conflicting outcomes. This issue may be due to differences in the strategies of administration as well as the types of antibodies. ${ }^{95-97}$ Improved phagocytosis rate of mycobacteria has been shown following the administration of sera from the vaccinated patients with BCG. This intervention could also enhance the ability of macrophages in killing the intracellular M. tuberculosis. ${ }^{98}$

\section{Conclusion}

Many studies have been performed on the promising immunotherapy of TB. The immunotherapy may contribute to improve the management and control of MDR/XDR TB cases. A third of population are infected with $M$. tuberculosis. Hence, immunotherapeutic approaches which can help to eliminate the latent infection with $M$. tuberculosis could have a marked impression on TB control. The impacts of novel immunotherapeutics/ vaccines on the reactivation or the progression of latent cases of TB in humans need to be further studied.

\section{Ethical Approval \\ Not applicable.}




\section{Competing Interests}

Authors declare that they have no competing interests.

\section{References}

1. Glaziou P, Sismanidis C, Floyd K, Raviglione M. Global epidemiology of tuberculosis. Cold Spring Harb Perspect Med. 2014;5(2):a017798. doi:10.1101/cshperspect. a017798.

2. Mert A, Bilir M, Tabak F, et al. Miliary tuberculosis: clinical manifestations, diagnosis and outcome in 38 adults. Respirology. 2001;6(3):217-224.

3. Brighenti $\mathrm{S}$, Andersson J. Induction and regulation of CD8 ${ }^{+}$ cytolytic T cells in human tuberculosis and HIV infection. Biochem Biophys Res Commun. 2010;396(1):50-57. doi: 10.1016/j.bbrc.2010.02.141.

4. Seder RA, Darrah PA, Roederer M. T-cell quality in memory and protection: implications for vaccine design. Nat Rev Immunol. 2008;8(4):247-258. doi: 10.1038/ nri2274.

5. Han Q, Bagheri N, Bradshaw EM, Hafler DA, Lauffenburger DA, Love JC. Polyfunctional responses by human $\mathrm{T}$ cells result from sequential release of cytokines. Proc Natl Acad Sci U S A. 2012;109(5):1607-1612. doi: 10.1073/pnas.1117194109.

6. Rook GA, Lowrie DB, Hernández-Pando R. Immunotherapeutics for tuberculosis in experimental animals: is there a common pathway activated by effective protocols? J Infect Dis. 2007;196(2):191-198.

7. Rook GA, Dheda K, Zumla A. Immune systems in developed and developing countries; implications for the design of vaccines that will work where BCG does not. Tuberculosis. 2006;86(3):152-162.

8. Rook GA, Dheda K, Zumla A. Immune responses to tuberculosis in developing countries: implications for new vaccines. Nat Rev Immunol. 2005;5(8):661-667.

9. Trinchieri G, Sher A. Cooperation of Toll-like receptor signals in innate immune defence. Nat Rev Immunol. 2007;7(3):179-190.

10. Ernst JD. Macrophage receptors for Mycobacterium tuberculosis. Infect Immun. 1998;66(4):1277-1281.

11. Schlesinger LS, Bellinger-Kawahara CG, Payne NR, Horwitz MA. Phagocytosis of Mycobacterium tuberculosis is mediated by human monocyte complement receptors and complement component C3. J Immunol. 1990;144(7):2771-2780.

12. Ferguson JS, Martin JL, Azad AK, et al. Surfactant protein D increases fusion of Mycobacterium tuberculosiscontaining phagosomes with lysosomes in human macrophages. Infect Immun. 2006;74(12):7005-7009.

13. Divangahi M, Mostowy S, Coulombe F, et al. NOD2deficient mice have impaired resistance to Mycobacterium tuberculosis infection through defective innate and adaptive immunity. J Immunol. 2008;181(10):7157-7165.

14. Korbel DS, Schneider BE, Schaible UE. Innate immunity in tuberculosis: myths and truth. Microbes Infect. 2008;10(9):995-1004

15. Liu PT, Modlin RL. Human macrophage host defense against Mycobacterium tuberculosis. Curr Opin Immunol. 2008;20(4):371-376.

16. Pathak SK, Basu S, Basu KK, et al. Direct extracellular interaction between the early secreted antigen ESAT-6 of Mycobacterium tuberculosis and TLR2 inhibits TLR signaling in macrophages. Nat Immunol. 2007;8(6):610618.

17. Liu PT, Stenger S, Li H, et al. Toll-like receptor triggering of a vitamin $\mathrm{D}$-mediated human antimicrobial response. Science. 2006;311(5768):1770-1773.

18. Chocano-Bedoya P, Ronnenberg AG. Vitamin D and tuberculosis. Nutr Rev. 2009;67(5):289-293.

19. Méndez-Samperio P. Role of antimicrobial peptides in host defense against mycobacterial infections. Peptides. 2008;29(10):1836-1841.

20. Liu PT, Stenger S, Tang DH, Modlin RL. Cutting edge: vitamin D-mediated human antimicrobial activity against Mycobacterium tuberculosis is dependent on the induction of cathelicidin. J Immunol. 2007;179(4):20602063.

21. Verreck FA, de Boer T, Langenberg DM, et al. Human IL-23-producing type 1 macrophages promote but IL10-producing type 2 macrophages subvert immunity to (myco) bacteria. Proc Natl Acad Sci U S A. 2004;101(13):4560-4565.

22. Savage ND, de Boer T, Walburg KV, et al. Human antiinflammatory macrophages induce Foxp3+ GITR+ CD25+ regulatory T cells, which suppress via membranebound TGF $\beta$-1. J Immunol. 2008;181(3):2220-2226.

23. Kaufmann SH. How can immunology contribute to the control of tuberculosis? Nat Rev Immunol. 2001;1(1):2030.

24. MacMicking JD, North RJ, LaCourse R, Mudgett JS, Shah SK, Nathan CF. Identification of nitric oxide synthase as a protective locus against tuberculosis. Proc Natl Acad Sci U S A. 1997;94(10):5243-5248.

25. Singh SB, Davis AS, Taylor GA, Deretic V. Human IRGM induces autophagy to eliminate intracellular mycobacteria. Science. 2006;313(5792):1438-1441.

26. MacMicking JD, Taylor GA, McKinney JD. Immune control of tuberculosis by IFN- $\gamma$-inducible LRG- 47 . Science. 2003;302(5645):654-659.

27. Gutierrez MG, Master SS, Singh SB, Taylor GA, Colombo MI, Deretic V. Autophagy is a defense mechanism inhibiting BCG and Mycobacterium tuberculosis survival in infected macrophages. Cell. 2004;119(6):753-766.

28. Harris J, De Haro SA, Master SS, et al. T helper 2 cytokines inhibit autophagic control of intracellular Mycobacterium tuberculosis. Immunity. 2007;27(3):505-517.

29. Flynn JL, Chan J. Tuberculosis: latency and reactivation. Infect Immun. 2001;69(7):4195-4201.

30. Martineau AR, Newton SM, Wilkinson KA, et al. Neutrophil-mediated innate immune resistance to mycobacteria. J Clin Invest. 2007;117(7):1988-1994.

31. Persson YAZ, Blomgran-Julinder R, Rahman S, Zheng L, Stendahl O. Mycobacterium tuberculosis-induced apoptotic neutrophils trigger a pro-inflammatory response in macrophages through release of heat shock protein 72 , acting in synergy with the bacteria. Microbes Infect. 2008;10(3):233-240. doi: 10.1016/j.micinf.2007.11.007..

32. Soehnlein O, Weber C, Lindbom L. Neutrophil granule proteins tune monocytic cell function. Trends Immunol. 2009;30(11):538-546. doi: 10.1016/j.it.2009.06.006. 
33. Cook JL. Pathogenesis of Human Pulmonary Tuberculosis: Insights from the Rabbit Model By Arthur M. Dannenberg, Jr. Washington, DC: ASM Press; 2006.

34. Khader SA, Partida-Sanchez S, Bell G, et al. Interleukin $12 \mathrm{p} 40$ is required for dendritic cell migration and $\mathrm{T}$ cell priming after Mycobacterium tuberculosis infection. J Exp Med. 2006;203(7):1805-1815.

35. Schaible UE, Winau F, Sieling PA, et al. Apoptosis facilitates antigen presentation to T lymphocytes through MHC-I and CD1 in tuberculosis. Nat Med. 2003;9(8):1039-1046.

36. Ngai P, McCormick S, Small C, et al. Gamma interferon responses of CD4 and CD8 T-cell subsets are quantitatively different and independent of each other during pulmonary Mycobacterium bovis BCG infection. Infect Immun. 2007;75(5):2244-2252.

37. Kaufmann SH, McMichael AJ. Annulling a dangerous liaison: vaccination strategies against AIDS and tuberculosis. Nat Med. 2005;11:S33-S44.

38. Wang J, Santosuosso M, Ngai P, Zganiacz A, Xing Z. Activation of CD8 $\mathrm{T}$ cells by mycobacterial vaccination protects against pulmonary tuberculosis in the absence of CD4 T cells. J Immunol. 2004;173(7):4590-4597.

39. Flynn JL, Chan J, Triebold KJ, Dalton DK, Stewart TA, Bloom BR. An essential role for interferon gamma in resistance to Mycobacterium tuberculosis infection. J Exp Med. 1993;178(6):2249-2254.

40. Surcel H, Troye-Blomberg M, Paulie S, et al. Th1/Th2 profiles in tuberculosis, based on the proliferation and cytokine response of blood lymphocytes to mycobacterial antigens. Immunology. 1994;81(2):171.

41. Zhang M, Lin Y, Iyer DV, Gong J, Abrams JS, Barnes $\mathrm{PF}$. T-cell cytokine responses in human infection with Mycobacterium tuberculosis. Infect Immun. 1995;63(8):3231-3234.

42. Kaufmann SH, Parida SK. Tuberculosis in Africa: learning from pathogenesis for biomarker identification. Cell Host Microbe. 2008;4(3):219-228. doi: 10.1016/j. chom.2008.08.002.

43. Dorhoi A, Kaufmann SH. Fine-tuning of T cell responses during infection. Curr Opin Immunol. 2009;21(4):367377. doi: 10.1016/j.coi.2009.07.004.

44. Joosten SA, Ottenhoff TH. Human CD4 and CD8 regulatory $\mathrm{T}$ cells in infectious diseases and vaccination. Hum Immunol. 2008;69(11):760-770. doi: 10.1016/j. humimm.2008.07.017.

45. Scott-Browne JP, Shafiani S, Ishida-Tsubota K, et al. Expansion and function of Foxp3-expressing T regulatory cells during tuberculosis. J Exp Med. 2007;204(9):21592169.

46. Li L, Wu C-Y. CD4+ CD25+ Treg cells inhibit human memory $\gamma \delta$ T cells to produce IFN- $\gamma$ in response to $M$ tuberculosis antigen ESAT-6. Blood. 2008;111(12):56295636. doi: 10.1182/blood-2008-02-139899.

47. Kursar M, Koch M, Mittrücker $\mathrm{H}-\mathrm{W}$, et al. Cutting Edge: Regulatory $\mathrm{T}$ cells prevent efficient clearance of Mycobacterium tuberculosis. J Immunol. 2007;178(5):2661-2665.

48. Rahman S, Gudetta B, Fink J, et al. Compartmentalization of immune responses in human tuberculosis: few CD8+ effector T cells but elevated levels of FoxP3+ regulatory $\mathrm{t}$ cells in the granulomatous lesions. Am J Pathol. 2009;174(6):2211-2224. doi: 10.2353/ajpath.2009.080941.

49. Chiacchio T, Casetti R, Butera O, et al. Characterization of regulatory $\mathrm{T}$ cells identified as CD4+ CD25highCD39+ in patients with active tuberculosis. Clin Exp Immunol. 2009;156(3):463-470.

50. Jaron B, Maranghi E, Leclerc C, Majlessi L. Effect of attenuation of Treg during BCG immunization on antimycobacterial Th1 responses and protection against Mycobacterium tuberculosis. PloS One. 2008;3(7):e2833. doi: 10.1371/journal.pone.0002833.

51. Bayry J, Tchilian EZ, Davies MN, et al. In silico identified CCR4 antagonists target regulatory $\mathrm{T}$ cells and exert adjuvant activity in vaccination. Proc Natl Acad Sci U S A. 2008;105(29):10221-10226.

52. Abebe F, Bjune G. The protective role of antibody responses during Mycobacterium tuberculosis infection. Clin Exp Immunol. 2009;157(2):235-243.

53. Maglione PJ, Chan J. How B cells shape the immune response against Mycobacterium tuberculosis. Eur J Immunol. 2009;39(3):676-686.

54. Carroll MV, Lack N, Sim E, Krarup A, Sim RB. Multiple routes of complement activation by Mycobacterium bovis BCG. Mol Immunol. 2009;46(16):3367-3378. doi: 10.1016/j.molimm.2009.07.015.

55. Bettelli E, Carrier Y, Gao W, et al. Reciprocal developmental pathways for the generation of pathogenic effector TH17 and regulatory T cells. Nature. 2006;441(7090):235-238.

56. Johnson JL, Kamya RM, Okwera A, et al. Randomized controlled trial of Mycobacterium vaccae immunotherapy in non-human immunodeficiency virus-infected Ugandan adults with newly diagnosed pulmonary tuberculosis. J Infect Dis. 2000;181(4):1304-1312.

57. Johnson J, Nunn A, Fourie P, et al. Effect of Mycobacterium vaccae (SRL172) immunotherapy on radiographic healing in tuberculosis. Int J Tuberc Lung Dis. 2004;8(11):13481354.

58. Yang X-Y, Chen Q-F, Li Y-P, Wu S-M. Mycobacterium vaccae as adjuvant therapy to anti-tuberculosis chemotherapy in never-treated tuberculosis patients: a meta-analysis. PloS One. 2011;6(9):e23826. doi: 10.1371/ journal.pone.0023826.

59. Butov DA, Efremenko YV, Prihoda ND, et al. Randomized, placebo-controlled Phase II trial of heat-killed Mycobacterium vaccae (Immodulon batch) formulated as an oral pill (V7). Immunotherapy. 2013;5(10):1047-1054.

60. Gupta A, Ahmad FJ, Ahmad F, et al. Efficacy of Mycobacterium indicus pranii immunotherapy as an adjunct to chemotherapy for tuberculosis and underlying immune responses in the lung. PloS One. 2012;7(7):e39215. doi: 10.1371/journal.pone.0039215.

61. Lowrie DB, Silva CL. Enhancement of immunocompetence in tuberculosis by DNA vaccination. Vaccine. 2000;18(16):1712-1716.

62. Okada M, Kita Y, Nakajima T, et al. Novel prophylactic vaccine using a prime-boost method and hemagglutinating virus of Japan-envelope against tuberculosis. Clin Dev Immunol. 2011;2011:549281. doi: 10.1155/2011/549281.

63. Tanghe A, D'Souza S, Rosseels V, et al. Improved immunogenicity and protective efficacy of a tuberculosis 
DNA vaccine encoding Ag85 by protein boosting. Infect Immun. 2001;69(5):3041-3047.

64. Derrick SC, Yang AL, Morris SL. A polyvalent DNA vaccine expressing an ESAT6-Ag85B fusion protein protects mice against a primary infection with Mycobacterium tuberculosis and boosts BCG-induced protective immunity. Vaccine. 2004;23(6):780-788.

65. Okada M, Kita Y, Nakajima T, et al. Novel therapeutic vaccine: granulysin and new DNA vaccine against Tuberculosis. Hum Vaccin. 2011;7:60-67. doi: 10.4161/ hv.7.0.14563.

66. Cardona P-J, Amat I, Gordillo S, et al. Immunotherapy with fragmented Mycobacterium tuberculosis cells increases the effectiveness of chemotherapy against a chronical infection in a murine model of tuberculosis. Vaccine. 2005;23(11):1393-1398.

67. Vilaplana C, Gil O, Cáceres N, Pinto S, Díaz J, Cardona P-J. Prophylactic effect of a therapeutic vaccine against TB based on fragments of Mycobacterium tuberculosis. PloS One. 2011;6(5):e20404. doi: 10.1371/journal. pone.0020404.

68. Vilaplana C, Montané E, Pinto S, et al. Double-blind, randomized, placebo-controlled Phase I Clinical Trial of the therapeutical antituberculous vaccine $\mathrm{RUTI}^{\circledR}$. Vaccine. 2010;28(4):1106-1116.

69. Nell AS, D’lom E, Bouic P, et al. Safety, tolerability, and immunogenicity of the novel antituberculous vaccine RUTI: randomized, placebo-controlled phase II clinical trial in patients with latent tuberculosis infection. PloS One. 2014;9(2):e89612. doi: 10.1371/journal. pone.0089612.

70. Herzog EL, Chai L, Krause DS. Plasticity of marrowderived stem cells. Blood. 2003;102(10):3483-3493.

71. Skrahin A, Ahmed RK, Ferrara G, et al. Autologous mesenchymal stromal cell infusion as adjunct treatment in patients with multidrug and extensively drug-resistant tuberculosis: an open-label phase 1 safety trial. Lancet Respir Med. 2014;2(2):108-122. doi: 10.1016/S22132600(13)70234-0.

72. Hogan BL, Yingling JM. Epithelial/mesenchymal interactions and branching morphogenesis of the lung. Curr Opin Genet Dev. 1998;8(4):481-486.

73. Sabatini F, Petecchia L, Tavian M, de Villeroché VJ, Rossi GA, Brouty-Boyé D. Human bronchial fibroblasts exhibit a mesenchymal stem cell phenotype and multilineage differentiating potentialities. Lab Invest. 2005;85(8):962971. doi:10.1038/labinvest.3700300.

74. Tropea KA, Leder E, Aslam M, et al. Bronchioalveolar stem cells increase after mesenchymal stromal cell treatment in a mouse model of bronchopulmonary dysplasia. Am J Physiol Lung Cell Mol Physiol. 2012;302(9):L829-L837. doi: 10.1152/ajplung.00347.2011.

75. Sinclair K, Yerkovich ST, Chambers DC. Mesenchymal stem cells and the lung. Respirology. 2013;18(3):397-411. doi: 10.1111/resp.12050.

76. Joshi L, Chelluri LK, Gaddam S. Mesenchymal stromal cell therapy in MDR/XDR tuberculosis: a concise review. Arch Immunol Ther Exp (Warsz). 2015;63(6):427-433. doi: 10.1007/s00005-015-0347-9.

77. Batdelger D, Dandii D, Jirathitikal V, Bourinbaiar AS.
Open-label trial of therapeutic immunization with oral V-5 Immunitor (V5) vaccine in patients with chronic hepatitis C. Vaccine. 2008;26(22):2733-2737. doi: 10.1016/j.vaccine.2008.03.021.

78. Butov DA, Pashkov YN, Stepanenko AL, et al. Phase IIb randomized trial of adjunct immunotherapy in patients with first-diagnosed tuberculosis, relapsed and multi-drug-resistant (MDR) TB. J Immune Based Ther Vaccines. 2011;9(1):1. doi: 10.1186/1476-8518-9-3.

79. Arjanova OV, Prihoda ND, Yurchenko LV, et al. Adjunct oral immunotherapy in patients with retreated, multidrug-resistant or HIV-coinfected TB. Immunotherapy. 2011;3(2):181-191.

80. Butov DA, Efremenko YV, Prihoda ND, et al. Adjunct immune therapy of first-diagnosed $\mathrm{TB}$, relapsed $\mathrm{TB}$, treatment-failed $\mathrm{TB}$, multidrug-resistant $\mathrm{TB}$ and $\mathrm{TB} /$ HIV. Immunotherapy. 2012;4(7):687-695. doi: 10.2217/ imt.12.59.

81. Condos R, Rom WN, Schluger NW. Treatment of multidrug-resistant pulmonary tuberculosis with interferon- $\gamma$ via aerosol. Lancet. 1997;349(9064):15131515.

82. Giosue S, Casarini M, Ameglio F, et al. Aerosolized interferon-alpha treatment in patients with multi-drugresistant pulmonary tuberculosis. Eur Cytokine Netw. 2000;11(1):99-104.

83. Koh W-J, Kwon OJ, Suh GY, et al. Six-month therapy with aerosolized interferon- $\gamma$ for refractory multidrugresistant pulmonary tuberculosis. J Korean Med Sci. 2004;19(2):167-171.

84. Balu S, Reljic R, Lewis MJ, et al. A novel human IgA monoclonal antibody protects against tuberculosis. J Immunol. 2011;186(5):3113-3119. doi: 10.4049/ jimmunol.1003189.

85. Johnson B, Bekker L, Rickman R, et al. rhulL-2 adjunctive therapy in multidrug resistant tuberculosis: a comparison of two treatment regimens and placebo. Tuber Lung Dis. 1997;78(3):195-203.

86. Johnson JL, Ssekasanvu E, Okwera A, et al. Randomized trial of adjunctive interleukin-2 in adults with pulmonary tuberculosis. Am J Respir Crit Care Med. 2003;168(2):185191.

87. Shen $\mathrm{H}$, Min $\mathrm{R}$, Tan $\mathrm{Q}$, et al. The beneficial effects of adjunctive recombinant human interleukin-2 for multidrug resistant tuberculosis. Arch Med Sci. 2015;11(3):584-590. doi: 10.5114/aoms.2015.52362.

88. Chen CY, Yao S, Huang D, et al. Phosphoantigen/IL2 expansion and differentiation of $\mathrm{V} \gamma 2 \mathrm{~V} \delta 2 \mathrm{~T}$ cells increase resistance to tuberculosis in nonhuman primates. PLoS Pathog. 2013;9(8):e1003501. doi: 10.1371/journal. ppat. 1003501.

89. Fallahi-Sichani M, Flynn JL, Linderman JJ, Kirschner DE. Differential risk of tuberculosis reactivation among anti-TNF therapies is due to drug binding kinetics and permeability. J Immunol. 2012;188(7):3169-3178. doi: 10.4049/jimmunol.1103298.

90. Wallis RS, Kyambadde P, Johnson JL, et al. A study of the safety, immunology, virology, and microbiology of adjunctive etanercept in HIV-1-associated tuberculosis. AIDS. 2004;18(2):257-264. 
91. Hernández-Pando R, Orozco-Esteves H, Maldonado H, et al. A combination of a transforming growth factor- $\beta$ antagonist and an inhibitor of cyclooxygenase is an effective treatment for murine pulmonary tuberculosis. Clin Exp Immunol. 2006;144(2):264-272. doi: 10.1111/j.1365-2249.2006.03049.x.

92. Roy E, Brennan J, Jolles S, Lowrie DB. Beneficial effect of anti-interleukin- 4 antibody when administered in a murine model of tuberculosis infection. Tuberculosis. 2008;88(3):197-202.

93. Vordermeier H, Venkataprasad N, Harris D, Ivanyi J. Increase of tuberculous infection in the organs of B celldeficient mice. Clin Exp Immunol. 1996;106(2):312-316.

94. Maglione PJ, Xu J, Chan J. B cells moderate inflammatory progression and enhance bacterial containment upon pulmonary challenge with Mycobacterium tuberculosis. J Immunol. 2007;178(11):7222-7234.

95. López Y, Yero D, Falero-Diaz G, et al. Induction of a protective response with an IgA monoclonal antibody against Mycobacterium tuberculosis $16 \mathrm{kDa}$ protein in a model of progressive pulmonary infection. Int J Med Microbiol. 2009;299(6):447-452. doi: 10.1016/j. ijmm.2008.10.007.

96. Roy E, Stavropoulos E, Brennan J, et al. Therapeutic efficacy of high-dose intravenous immunoglobulin in Mycobacterium tuberculosis infection in mice. Infect Immun. 2005;73(9):6101-6109.

97. Hamasur B, Haile M, Pawlowski A, Schröder U, Källenius G, Svenson S. A mycobacterial lipoarabinomannan specific monoclonal antibody and its $\mathrm{F}\left(\mathrm{ab}^{\prime}\right) 2$ fragment prolong survival of mice infected with Mycobacterium tuberculosis. Clin Exp Immunol. 2004;138(1):30-38.

98. De Valliere S, Abate G, Blazevic A, Heuertz R, Hoft D. Enhancement of innate and cell-mediated immunity by antimycobacterial antibodies. Infect Immun. 2005;73(10):6711-6720. 